\title{
Fenestration of the vertebral artery: case presentation
}

\author{
H. Tetiker ${ }^{1}$, M. Çimen ${ }^{2}$, M.I. Koşar ${ }^{1}$ \\ ${ }^{1}$ Department of Anatomy, Muğla Sıtkı Koçman University, Faculty of Medicine, Muğla, Turkey \\ ${ }^{2}$ Department of Anatomy, Cumhuriyet University, Faculty of Medicine, Sivas, Turkey
}

[Received 19 June 2013; Accepted 31 July 2013]

\begin{abstract}
Fenestrations of vertebral arteries are considered to be rare abnormalities observed in angiographic and autopsy studies. They result from vascular abnormalities that occur during the embryological development of vertebral artery. Fenestrations of the vertebral artery are vascular structures having 2 different lumens and endothelium layers, sharing either the same or separate adventitia layers. As a result of the carotid Doppler ultrasonography performed on a 65-year-old woman applying to the Neurology Clinic of Cumhuriyet University Faculty of Medicine, Research and Practice Hospital with the complaints of vertigo and numbness in the head, a plaque leading to $60 \%$ stenosis in the right internal carotid artery, close to the place of initiation was seen. The patient, whose vertebral artery lumen structures and calibrations have found to be normal in the Doppler ultrasonography of vertebral artery, was scheduled for double-sided selective carotid and vertebral artery angiography. With the performed digital subtraction angiography imaging method, an atheroma plaque, extending to internal carotid artery proximal starting from sinus caroticus through the right internal carotid artery and leading to $50 \%$ stenosis, having the appearance of an ulcer, was observed. In the vertebral artery angiography of the case, while the right vertebral artery was found to be normal, fenestration in the upper cervical segment was observed in the left vertebral artery. This situation has been presented in this paper with radiological and embryological evaluation. (Folia Morphol 2014; 73, 1: 84-86)
\end{abstract}

Key words: vertebral artery, fenestration, digital subtraction angiography

\section{INTRODUCTION}

Vertebral artery (VA) starts in the root of neck as the first branch of the subclavian artery. It divides into 4 segments as V1, V2, V3 and V4. V1 segment is the part starting from the origin to the foramen transversarium of the $6^{\text {th }}$ cervical vertebra and is named as pars prevertebralis. After this point, each artery rises through the foramina transversaria of the upper cervical vertebrae successively and comes to the top of foramen transversarium of the atlas. This part is called V2 segment or pars vertebralis. After it leaves the foramen transversarium of VA of atlas, it has a horizontal course and penetrates the dura mater around foramen magnum. This part is known as V3 segment or suboccipital segment. The artery progresses in the subarachnoid interval in the cavum cranii, joins with the VA of the opposite side at the lower margin of the pons and constitutes basilar artery. This is the last segment of the artery and is named as pars intracranialis or V4 segment. 
Fenestrations of cerebral arteries are separate vascular structures or the same vascular structures that have separate lumen and endothelium layers, but sharing the same adventitia layer $[8,14]$. This abnormality is also named as 'bypass abnormality' or 'partial dublication' [13]. Fenestration of the VA is considered to arise from the anastomose abnormality of the cervical segmental arteries during the embryological development of $\mathrm{VA}$, and this has been first expressed by Padget $[3,6]$.

Fenestrations of VA are 2 main configurations as arterial split and true fenestrations. While true fenestrations have relatively wider arterial windows, arterial splits are considered to be intraluminal defects. Fenestrations of VA are either present in extracranial VA at the atlantoaxial level, or in the intracranial segment of the VA. Fenestration of extracranial VA may rarely be found below the C2 level [13].

While the incidence of fenestration of VA was between $0.23 \%$ and $1.90 \%$ in the angiographic studies, it is $0.33 \%$ in the autopsy series. Until now, fenestration of VA in more than 100 cases was angiographically reported in the literature. Nearly $70 \%$ of them are observed to be present in the upper cervical segment, and the rest are observed to be present intracranially [12]. In this paper, the fenestration of the left VA observed at the atlantoaxial level was evaluated in a female case with digital subtraction angiography method.

\section{CASE REPORT}

A 65-year-old female having the complaints of vertigo and numbness in the head for 2 years has recently applied to the Neurology Clinic due to the increase in her complaints. In tshe carotid Doppler ultrasonography of the patient who has a history of hypertension, diabetes mellitus and coronary artery disease, a plaque leading to $60 \%$ stenosis in the right internal carotid artery, close to the place of initiation, was seen. In the Doppler ultrasonography of the VA, lumen structures and calibrations of both sides were normal. In the spectral analysis, flow patterns of VA were evaluated to be normal. The patient, whose average VA volumes were calculated to be normal ( $\mathrm{N}>200 \mathrm{~mL} / \mathrm{min}$ ) was scheduled for double-sided selective carotid and VA angiography. In the double-sided selective carotid and 4-system selective cerebral digi-

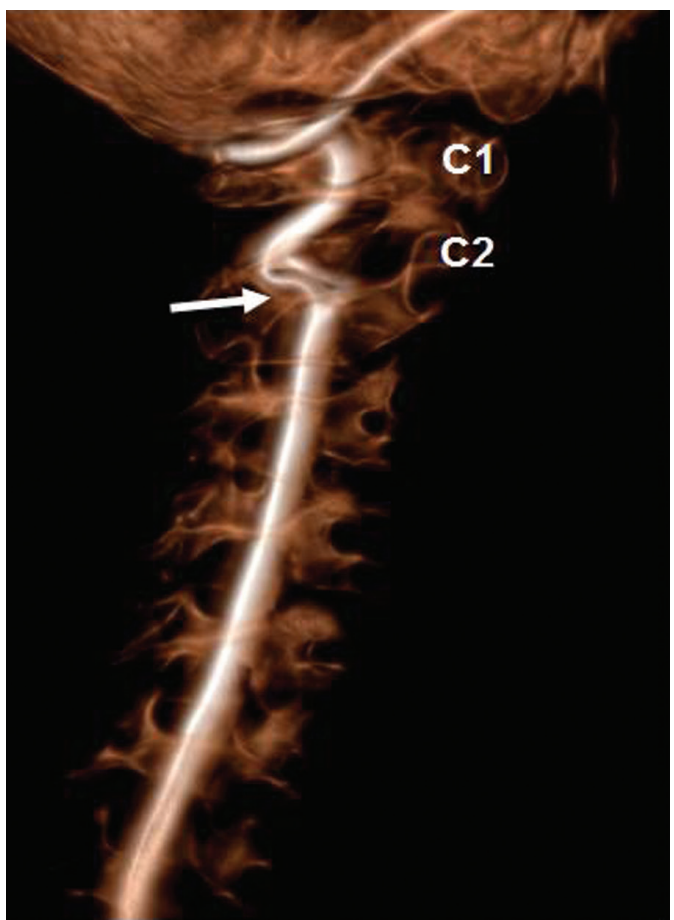

Figure 1. Oblique view of the left vertebral artery (LVA) fenestration at the V2 segment. Fenestration is observed in the LVA of the female case after exiting the foramen transversarium of the axis. The 2 lumens that are produced, joins again before reaching the atlas; $\mathrm{C} 1$ - atlas, $\mathrm{C} 2$ - axis.

tal subtraction angiography (DSA) examination performed by right femoral artery catheterisation using DSA imaging method, an atheroma plaque, extending to internal carotid artery proximal starting from sinus caroticus through right internal carotid artery and leading to $50 \%$ stenosis having the appearance of an ulcer, was observed. An atheroma plaque, extending to the proximal of right external carotid artery that does not lead to significant stenosis was present.

In the vertebral artery angiography of the case, right VA was found to be normal, however, fenestration was observed in the upper cervical segment of the left VA, at the atlantoaxial level. This originates from the left subclavian artery, which is the normal origin of the left VA and enters into the spinal column at the $\mathrm{C} 6$ foramen transversarium level. After exiting from the foramen transversarium of the axis, it separates with bifurcation and joins again before reaching atlas. The artery continued its usual course after passing the foramen transversarium of the atlas (Fig. 1). 


\section{DISCUSSION}

Fenestration of the vertebral artery comprises of parallel segments that are seen in any point during the course of the VA. It is sometimes mistaken for VA that has 2 origins (double originated VA) joining at different levels [12]. Fenestration is frequently found at the atlantoaxial resultant level on the left. It is rarely bilateral [3, 10]. Kowada and Kikuchi [3] demonstrated fenestration abnormality in the left VA of 2 cases at the atlantoaxial level. Rieger and Huber [7], and Iwamuro et al. [2] reported left VA having fenestration abnormality at the atlantoaxial level. Tseng et al. [12] reported left VA with fenestration abnormality between the C4-C6 foramina transversaria.

Though the case that we have been reporting does not specify the origin, it shows similarity with the cases that Kowada and Kikuchi [3], Rieger and Huber [7], and Iwamuro et al. [2] have described in regard to the level and the course.

Fenestration of the VA is a rarely seen abnormality. In the literature, different ratios are given in respect to the incidence of this abnormality. Rieger and Huber [7] reported the incidence as 0.23-1.95 in angiography and $0.33 \%$ in autopsy; Tokuda et al. [10] reported the incidence as $1.00 \%$ in angiography, and Kowada et al. [4] reported the incidence as $1.90 \%$ in angiography.

Fenestration of the VA is considered to be a developmental abnormality that occurs during the embryonic period [5]. Embryologically, the development of VA starts on the $32^{\text {nd }}$ day and is completed on the $40^{\text {th }}$ day $[6,9]$. According to the description of Padget [6], on the $32^{\text {th }}$ day of the embryonic period, plexiform and longitudinal anastomotic connections develop from the intersegmental arteries that are formed out of primitive dorsal aorta. After that, with the continuing transformation of the anastomoses to a single lumen, primitive VA forms. Meanwhile, the first 6 cervical intersegmental arteries except for the $7^{\text {th }}$ cervical intersegmental artery undergo regression. $7^{\text {th }}$ cervical intersegmental artery forms the proximal part of subclavian artery that also includes the origin of VA. Fenestrations of VA arise as a result of the disorder during the transformation of plexiform anastomoses into a single vascular channel. Some anastomotic channels are permanent. This opinion may explain the formation of complex fenestrations.

Some authors state that fenestration of the VA is an incidental finding and has no significant patho- logical and clinical results [1]. However, some other authors report that it increases the prevalence of aneurisms and vascular pathology, and is also associated with brain, spinal cord and spinal column abnormalities [11]. In our case, this fenestration of the VA is an incidental finding and, as observed in angiography, could not be associated with other intracranial or extracranial abnormalities.

Knowing abnormalities like fenestrations of VA should be considered both in the diagnosis and in the surgical interventions performed in the atlantoaxial resultant.

\section{REFERENCES}

1. Ionete C, Omojola MF (2006) MR angiographic demonstration of bilateral duplication of the extracranial vertebral artery: unusual course and review of the literature. Am J Neuroradiol, 27: 1034-1006.

2. Iwamuro Y, Miyake H, Akiyama Y, Ito T, Kumai J, Matsumoto Y, Sugino T (1995) Infantile brainstem infarction due to vertebral artery fenestration: a case report. No Shinkei Geka, 23: 1045-1049.

3. Kowada M, Kikuchi K (1979) Symmetrical extracranial fenestration of the vertebral artery: two cases revealed by angiography. Radiology, 131: 408.

4. Kowada M, Yamaguchi K, Takahashi H (1972) Fenestration of the vertebral artery with a review of 23 cases in Japan. Radiology, 103: 343-346.

5. Lasjaunias P (1983) Craniofacial and upper cervical arteries: collateral circulations and angiographic protocols. Williams and Wilkins, Baltimore, pp. 15-27.

6. Padget DH (1948) The development of cranial arteries in the human embryo. Contrib Embryol, 32: 207-261.

7. Rieger P, Huber G (1983) Fenestration and duplicate origin of the left vertebral artery in angiography. Report of three cases. Neuroradiology, 25: 45-50.

8. Sanders WP, Sorek PA, Mehta BA (1993) Fenestration of intracranial arteries with special attention to associated aneurysms and other anomalies. Am J Neuroradiol, 14: 675-680.

9. Sim E, Vaccaro AR, Berzlanovich A, Thaler H, Ullrich CG (2011) Fenestration of the extracranial vertebral artery: review of the literature. Spine, 26: 139-142.

10. Tokuda K, Sugimoto S, Abe S, Takei H, Miyaskara K, Abe H, Tsuru M (1981) Angiographic analysis of anomalous vertebral arteries. Neuroradiology, 22: 47.

11. Tran-Dinh HD, Soo YS, Jayasinghe LS (1991) Duplication of the vertebro-basilar system. Aust Radiol, 35: 220-224.

12. Tseng YC, Hsu HL, Lee TH, Wang $\amalg$, Wong YC, Chen CJ (2004) Fenestration of the vertebral artery at the lower cervical segment: imaging findings and literature review. Radiology, 49: 37-40.

13. Uchino A, Sawada A, Takase Y, Kudo S (2002) Extreme fenestration of the right vertebral artery: magnetic resonance angiographic demonstration. Eur Radiol, 12: S32-S34.

14. Van Rooij SBT, van Rooij WJ, Sluzewski M, Sprengers MES (2009) Fenestrations of Intracranial arteries detected with 3D rotational angiography. Am J Neuroradiol, 30: 1347-1320. 